\title{
A PORTABLE PHOTOCELL FLUOROMETER FOR DILUTION MEASUREMENTS IN NATURAL WATERS ${ }^{1,2}$
}

\author{
Vincent E. Noble and John C. Ayers
}

Great Lakes Research Division, Institute of Science and Technology, University of Michigan, Ann Arbor

\begin{abstract}
A portable fluorometer for use with a fluorescent dye tracer in field measurements of dilution rates in natural waters has been designed and tested. The unit is inexpensive, accurate, and reliable. It requires only a small amount of a-c power.

The instrument has been used in a series of 24 measurements of the dilution rate in the surface waters of Little Traverse Bay, Lake Michigan. The dilution of a quantity of dyc introduced into the Bay is given by: $D(T)=r_{t}^{T / t}$ where $T$ is the time in minutes, and $t$ is a quantity expressing the dilution period of interest. The average value for the observed dilution ratio, under winds up to $10-12 \mathrm{mph}$, is $\left(r_{10}\right)_{\mathrm{av}}=2$ (i.e., an average dilution of $\mathrm{x} 2$ every $10 \mathrm{~min}$ ).
\end{abstract}

\section{INTRODUCTION}

Many problems of extreme practical interest to the limnologist and the sanitary engineer involve the dilution rates of influent waters and/or of contaminants in lakes and streams. Fluorescent dyes are demonstratedly excellent tracers of water movemonts, and, with suitable instrumentation, will also yield simultaneous data on the dilution rates inherent in the traced currents. This paper describes, and gives results from, a portable fluorometer developed for use with the fluorescent dye Rhodamine B (Pritchard 1960); the fluorometer is inexpensive, accurate, reliable, and portable.

Other diffusion studies reported in the literature have uscd fluorescein as the tracer and photomultiplier tubes as the detecting elements. The fluorometer described by Moon, Bretschneider, and Hood (1957) uses a photomultiplier to detect the presence of fluorescein with the same sensitivity of operation as the instrument described in the present paper. The visiblelight filters in the photocell fluorometer may be changed to accommodate fluorescein which is somewhat cheaper than the Rhodamine B used in this experiment. A

\footnotetext{
1. Supported in part by Consumers Power Co., Jackson, Mich.

${ }^{2}$ Contribution No. 10 from the Great Lakes Research Division, Institute of Science and Tcchnology, the University of Michigan, Ann Arbor.
}

commercial fluorometer which offers two orders of magnitude greater sensitivity is offered by G. K. Turner Associates.

\section{INSTRUMENTATION}

In order to maintain a flexibility of operation, the present equipment uses the inter-connection of several components rather than the construction of a single unit containing the fluorometer, sampling pump, and recorder. Figure 1 shows a block diagram of the complete fluorometer system. We have used an electric pump, operated from a portable generator, for continuous sampling. A hand pump for continuous sampling, or a batch process could also be used. The recorder may be either a recording potentiometer or a voltmeter, the requirements being that the measuring device must have a high input impedance and must be capable of covering a wide range of voltages. Using the suggested photocells and battery, an output voltage range of 0.1 to $35 \mathrm{v}$ has been obtained.

Figure 2 shows a schematic diagram of the construction of the fluorometer. The visible light emitted, under ultraviolet radi-

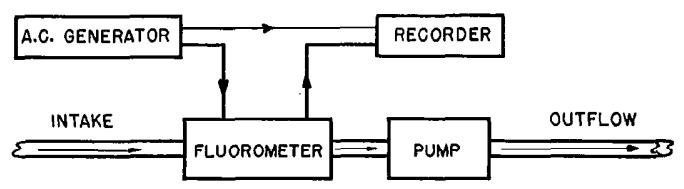

FIG. 1. Block diagram of the complete fluorometer system. 


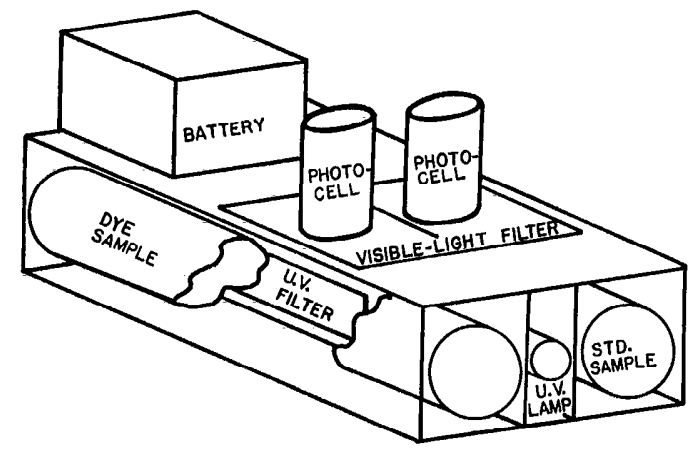

FIG. 2. Schematic diagram of fluorometer construction. In use the instrument stands with the left end down and the intake enters the bottom of the dye-sample tube.

ation, by water containing a fluorescent dye is compared with the emission from a standard cell containing natural lake water. A comparative technique is used to obtain reliability of measurement in the possible presence of variations in the intensity of the ultraviolet light source, systematic changes in the characteristics of the photocells, or differences in the amounts of naturally occurring fluorescent substances in the lake water.

A single 4-w ultraviolet lamp (Sylvania F4 T5/BLB) was used to illuminate the

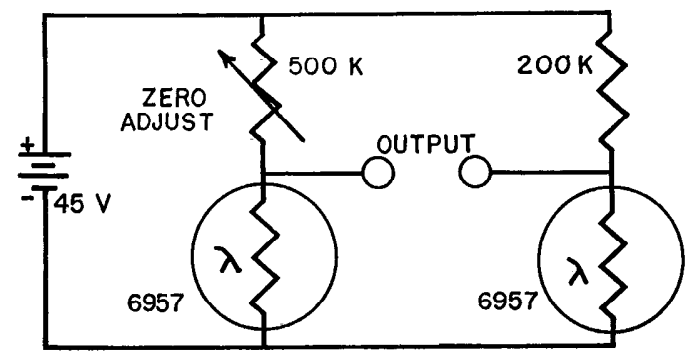

FIG. 3. Schematic diagram of the fluorometer circuit.

water in the sample and standard cells. The ultraviolet was filtered with Wratten No. 18A filters to remove as much visible light as possible. The sample cells were Plexiglas tubes of 1/1/4-in. internal diameter oriented parallel to the axis of the UV light. Plexiglas was used to obtain maximum transmission of the UV.

The sample tubes were mounted with their axes vertical so that any bubbles in the tubes would rise out of the range of the photocells. The standard cell consisted of a single sample of the regional water which was kept in a stoppered tube, while the dye sample was continuously pumped through a second tube equipped with hose fittings. The intake hose was connected to

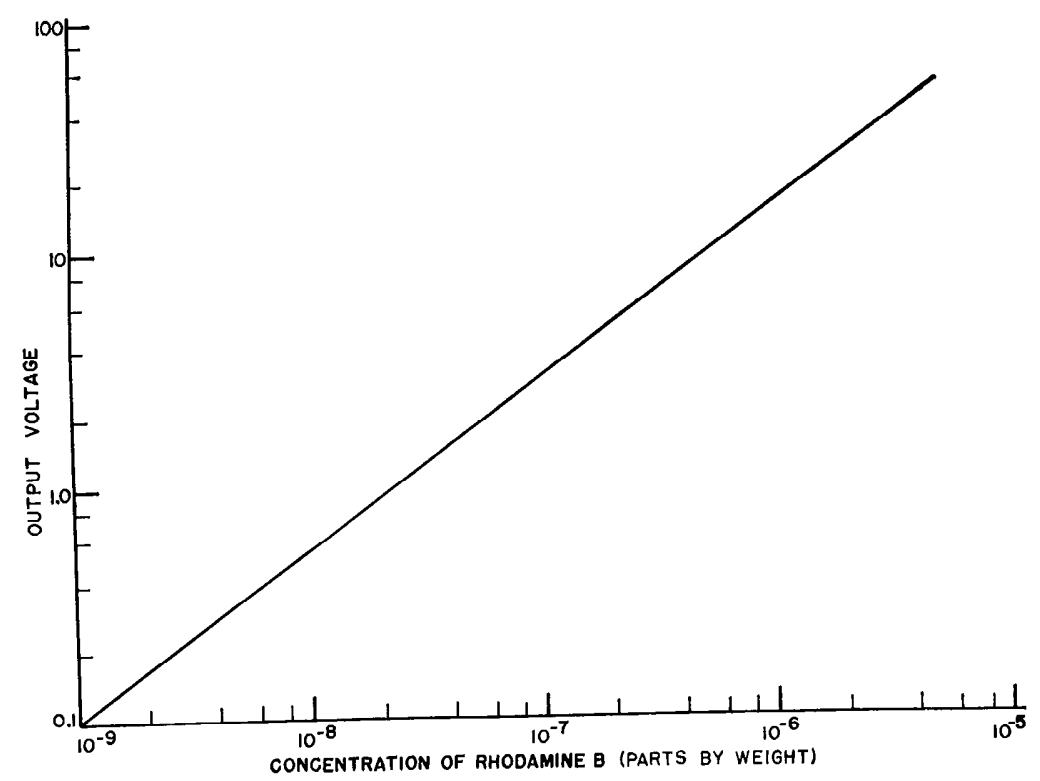

FIg. 4. Fluorometer calibration curve. 


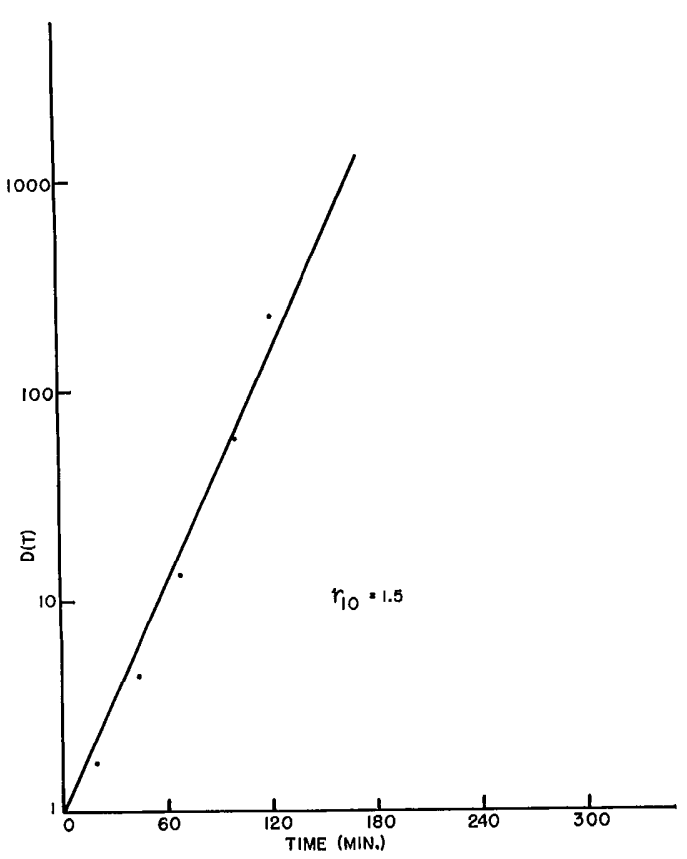

FIG. 5. Reprosentative dilution curve. $D(T)$ $=C_{0} / C(T)$. Single dye patch.

the bottom of the sample tube, and the sampling pump connected to the top, to eliminate any bubbles in the tube. The sampling pump was placed in the outflow from the fluorometer to prevent a possible accumulation of dye in the pump from contaminating the dye sample. The entire fluorometer was placed in a light-tight box to eliminate the effects of ambient light upon the photocells.

The photocells were oriented at $90^{\circ}$ to the source of UV light incident upon the samplc cells so that direct radiations from the light source could not be received by the photocells. Visible-light filters were placed between the sample cells and the photocells so that the photocells would respond only to the fluorescent wavelength of the dye contained in the sample water. In the present case, Rhodamine $B$ dye was used with a Wratten 25 filter. Rhodamine $B$ was chosen because of its fluorescence in visible light (thus permitting visual observation of the behavior of the dye patch) and because its fluorescent wavelength is not apt to be duplicated by substances

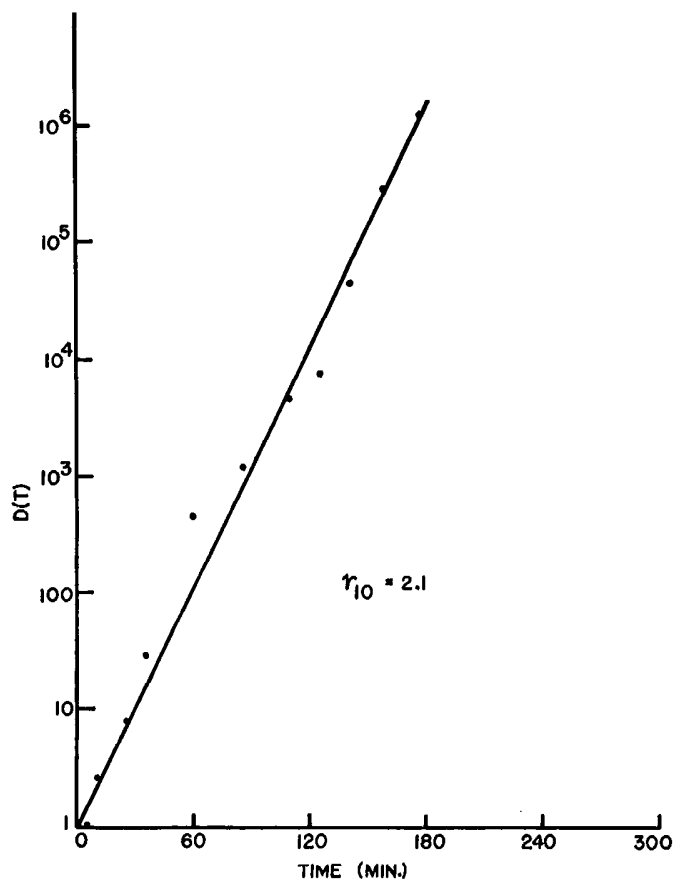

Frg. 6. Representative dilution curve. $D(T)$ $=C_{0} / C(T)$. Dye patch recharged at $T=35 \mathrm{~min}$, and again at $T=125 \mathrm{~min}$.

naturally present in the water prior to the introduction of the dye.

The schematic diagram of the electrical circuit of the fluorometer is shown in Figure 3 , and the calibration curve is shown in Figure 4. The fluorometer was calibrated by using standard-sample tubes containing known concentrations of dye in water taken from the region of interest. The use of the regional water minimizes the possibility of fluorescence of contaminants interfering with the results of the measurements.

By using a vacuum-tube voltmeter to measure the output signal from the fluorometer, the a-c power demands for the voltmeter and fluorometer would be sufficiently small to permit operation with a converter and a storage battery. Thus, if a handpump were used for sampling, the total unit would be sufficiently portable for field studies of the limnology of remote regions.

\section{EXPERIMENTAL METHODS}

Since the purpose of the program was the measurement of the dilution rates of 
surface waters, the stock dye solution was diluted with methanol in order to obtain a solution of specific gravity such that the dye patch would stay on the surface of the water during the course of the measurcments. In this series of measurements, one pint of a stock solution of Rhodamine B in $40 \%$ acetic acid solution was mixed with three quarts of methanol. The mixture stayed in the upper $10 \mathrm{ft}$ of the water, with the major portion of the dye less than $3 \mathrm{ft}$ from the surface.

After the dye was introduced, the research vessel was slowly coasted through the dye patch while a continuous sample was being pumped through the fluorometer. Successive passes were made through the dye, and the maximum observed dye concentration was recorded for each pass. By recording the concentration maxima, a minimum rate of dilution was obtained. A typical sequence might consist of passes through the dye patch every 10 or $20 \mathrm{~min}$ for a pcriod of $2 \mathrm{hr}$ (until the dye patch is too diffuse to measure accurately). As can be seen from the calibration curve, a dye concentration of $10^{-9}$ parts by weight in water can be measured quantitatively, and experience has shown that this concentration can be observed visually in the clear waters of Little Traverse Bay.

The path of the dye patch is observed, and if a prolonged sequence of measurement is required, a second dye patch may be introduced at the leading edge of the first patch when the first patch has become too diffuse to measure. The dilution of the second patch is then observed, and the total dilution occurring through the sequence of the two patches is the product of the dilution observed for the first patch multiplied by that of the second patch. A sequence of any number of patches may be treated in this manner.

The dye concentration as a function of time $C(T)$ is taken to be:

$$
C(T)=C_{0} f(T),
$$

where $C(T)$ is the maximum concentration observed in the dye patch at time $T$, and $C_{0}$ is the initial concentration, $C_{0}=C(T=0)$.

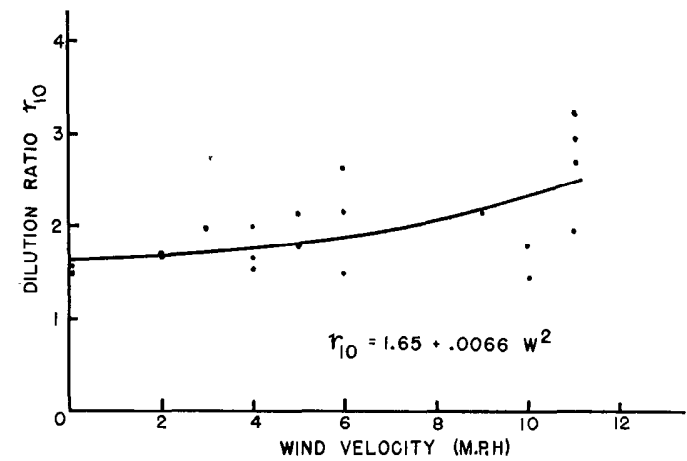

FIG. 7. Dilution ratio as a function of wind speed at the time of measurement.

The dilution is defined as:

$$
D(T)=C_{0} / C(T)=1 / f(T) .
$$

From relation (2), it is seen that the determination of the maximum values of the dye concentration (considered to be $C(T)$ ) will give minimum values for the dilution $D(T)$. Figures 5 and 6 show representative dilution curves obtained from the sequence of dilution measurements.

From the curves, it is seen that the dilution obeys the relation:

$$
\log D(T)=B T=-\log f(T)
$$

where $B$ is interpreted as:

$$
B=\frac{1}{t} \log r_{t} .
$$

The expression for the dilution becomes:

$$
D(T)=r_{t}^{T / t} \text {. }
$$

Equation (1) may therefore be written as:

$$
C(T)=C_{0} r_{t}^{-T / t} \text {. }
$$

In the above expressions, $t$ specifies the dilution period and $r_{t}$ is the dilution ratio (i.e., $r_{t}$ denotes a dilution by a factor of $r$ in a period of $t$ minutes ).

Consideration of the mechanics of the dilution process indicates the significance of $r_{t}$. The total amount of dye in the dye patch is a constant, and if a uniform concentration through the patch is assumed, the product of the dye concentration, $C$, with the total volume of the dye solution, $V$, is a constant:

$$
C V=B .
$$


TAliLe 1. Frequency distribution of dilution ratios (24 observations)

\begin{tabular}{cccc}
\hline $\begin{array}{c}\text { Dilution ratio } \\
\left(r_{10}\right)\end{array}$ & No. & $\begin{array}{c}\text { Dilution ratio } \\
\left(r_{10}\right)\end{array}$ & No. \\
\hline 1.4 & 3 & 2.1 & 3 \\
1.5 & 3 & 2.6 & 2 \\
1.6 & 3 & 2.9 & 1 \\
1.7 & 2 & 3.0 & 3 \\
1.9 & 1 & 3.2 & 1 \\
2.0 & 2 & \\
& & & \\
& &
\end{tabular}

Considering the dilution to proceed at a constant rate, the expression for the volume of the dye patch becomes a geometric series in time and may be written as:

$$
V(T)=V_{0} r_{t}^{(T / t)}
$$

where $V_{0}$ is the initial volume of the dye patch, and $r_{t}$ is the dilution ratio. Substituting equation (8) into equation (7), the expression for the dye concentration as a function of time becomes:

$$
\begin{aligned}
C(T) & =\left(B / V_{0}\right) r_{t}-(T / t) \\
& =C_{0} r_{t}-(T / t)
\end{aligned}
$$

This is the same expression as that obtained from the dilution measurements (equation 6 ), demonstrating that the dilution may be considered to proceed as a simple geometrical process.

\section{EXPERIMENTAL RESULTS}

The frequency distribution for the values of $r_{t}$ which have been obtained from the data is given in Table 1 . The corresponding distribution of observed current speeds for the motion of the dye patches is given in Table 2. The relation of the dilution ratio to the wind speed at the time of meassurement is shown in Figure 7. The curve has been fitted to the data by the least squares mothod (Goedicke 1953). The dilution ratio has been found to be independent of both the current speed and the distance traveled by the dye patch.

The average value of the dilution con-
TABLE 2. Frequency distribution of current speed ( 24 observations)

\begin{tabular}{cccccc}
\hline $\begin{array}{c}\text { Current } \\
\text { specd } \\
(\mathrm{mph})\end{array}$ & No. & $\begin{array}{c}\text { Current } \\
\text { spced } \\
(\mathrm{mph})\end{array}$ & No. & $\begin{array}{c}\text { Current } \\
\text { speed } \\
(\mathrm{mph})\end{array}$ & No. \\
\hline 0.09 & 1 & 0.27 & 2 & 0.42 & 1 \\
0.10 & 1 & 0.29 & 1 & 0.57 & 1 \\
0.15 & 1 & 0.31 & 1 & 0.64 & 1 \\
0.16 & 1 & 0.34 & 1 & 0.65 & 1 \\
0.18 & 1 & 0.35 & 1 & 0.68 & 1 \\
0.20 & 1 & 0.38 & 1 & 0.71 & 1 \\
0.21 & 2 & 0.41 & 1 & 1.05 & 1 \\
0.25 & 1 & & & &
\end{tabular}

stant, under light winds, is 2.0 for $t=10$ min, with a range of 1.4 to 3.2 . The average value for the current speed of the dye patch is $0.34 \mathrm{mph}$, under light winds, with a range of 0.09 to $1.05 \mathrm{mph}$. The relation betwcen the dilution ratio and the wind spced is given by:

$$
r_{10}=1.65+0.0066 W^{2} .
$$

The experimental method, in this case, has becn designed to yield figures for the minimum dilution rate in the surface waters of Little Traverse Bay. In computations of the expected dilution, it is necessary to use the straight-line transport velocity of the water mass (as opposed to the current speed of the dye patch along a meandering path) to obtain the time available for dilution as the contaminant moves from its point of origin to the region where its presence is of concern (the region for which the predicted dilution is computed).

\section{REFERENCES}

GoEnICKe, V. 1953. Introduction to the theory of statistics. Harper and Brothers, New York. p. 146.

Moon, F. W., Jr., C. L. Bretschneider, And D. W. Hoon. 1957. A method for measuring eddy diffusion in coastal embayments. Publ. Inst. Mar. Sci. Univ. Texas, 4: 14-21.

Pritchard, D. W. 1960 . Some preliminary results of dircet obscrvations on water movement and dispcrsion using a new fluorescent tracer technique. Paper given at Forty-first Annual Mceting, Am. Gcophys. Union, Washington, D. C. 